\title{
SOME ASPECTS REGARDING COMPACTION OF PLASTIC BOTTLES IN STATIONARY VERTICAL PRESSES
}

\author{
Mircea-Bucur Lazea, Gheorghe Voicu, Gabriel-Alexandru Constantin, \\ Paula Tudor, Bianca-Stefania Zabava \\ University Politehnica of Bucharest, Romania \\ lazea.mb@gmail.com,ghvoicu_2005@yahoo.com,gabriel_alex99@yahoo.com, \\ paula.tudor@upb.ro, bianca.dragoiu@yahoo.com
}

\begin{abstract}
The paper presents some aspects regarding the compaction of PET bottles in a stationary vertical press, the collection and recording of data continuously from the pressing equipment being an older concern of the authors. In this regard, the vertical press was supplemented with a system for measuring displacements and compaction forces, as well as a system for acquiring and recording experimental data. Thus, the forces necessary for the separate compaction, in batches of the PET bottles, by categories (2 litres) are presented, the compaction being done in successive stages until the maximum compaction force is reached and the volume specified by the manufacturer. 2-litre bottles were used, the compaction being done in 3 loading batches, with the same type of bottles, each batch having two or three successive compactions. In the case of 21 bottles, for a total stroke of the press plate, it was found that there is an empty stroke portion and a load stroke portion, for each compaction stage. The latter is all the bigger the fuller the pressing chamber. If at small quantities of material the displacement of the plate and the recording forces are small (about $139 \mathrm{daN}$ for 77 previously undeformed PET bottles), for larger fills the registered forces increase (they can reach 500-600 daN for 129 bottles, respectively 600-700 daN for 155 bottles in the pressing chamber). Corresponding to these forces, the energy consumed at deformation increases from about $130 \mathrm{~J}$ (in the first stage) to $1400-1700 \mathrm{~J}$ (in the second stage of compaction). For three phases of filling with material and seven stages of compression-recompression $(2+2+3)$, the average value of specific compression energy for the whole process was around $0.82 \mathrm{~kJ} \cdot \mathrm{kg}^{-1}$ of compressed material.
\end{abstract}

Keywords: plastic waste, stepped compacting, data acquisition system, pressure forces, displacement curves.

\section{Introduction}

Plastic packaging waste has become a particularly important issue for humanity. The volume occupied by this waste is huge and has a major impact on nature pollution on land or in water. The flow of recovery and recycling needs to be improved globally and locally [1;2]. For example, PET bottles are not received for recycling in all stores in Romania. We could even say that they are returned very little to be recycled. Instead, various entrepreneurs or individuals collect them. They are collected, pressed, baled, and then sent to the economic agents who make their recycling.

PET bottles are used for soft drinks, mineral water, energy drinks, cold teas, as well as for other beverages such as beer, wine and juices. Every year, many companies in the recovery and recycling network incur significant costs associated with the collection, sorting and recycling of used polymer packaging and PET bottles [1-5], the process of compacting plastic waste and biomass, including the phases that the compacted material goes through is being described in several papers [3; 6-9].

Recycling plastic bottles also involves decontamination processes to remove post-consumer contaminants, super-clean recycling processes are available today with bringing to concentration levels of virgin PET materials [5,10]. Conventional recycling begins with the collection of PET bottles, followed by grinding, washing, removal of lids and labels and transformation into PET flakes. After that follows re-extrusion of plastic, not before obtaining amorphous PET pellets, by melting and fluidizing at $280-290{ }^{\circ} \mathrm{C}$, with a vacuum degassing, and finally decontamination at $180-230^{\circ} \mathrm{C}$, for more than 6 hours with inert gas or vacuum, with obtaining crystalline PET pellets, through solid-state polycondensation [10].

Plastics, such as polyethylene terephthalate, polycarbonate and melamine, can be recycled by using them in building concrete or mortars in the form of granules or small particles as sand replacement aggregates [5; 11-13].

The first step in the process of recycling PET bottles is to collect and package them, when the bottles are not crushed directly at the big stores that collect these bottles. The baling of the collected bottles is, generally, done with the help of piston presses for compressing the material and reducing the volume in order to optimize the efficiency of storage and transport, possibly by tying the bale to maintain the dimensions and protect the material from the influence of the environment $[3 ; 5]$. 
A hydraulic press makes it possible to significantly reduce the costs of transporting recyclable materials and achieve a significant profit. PET bottles, in the form of compact bales, are much easier to pass on to companies that deal with their recycling.

The baling process is a simple one, especially if the press used is a small and medium capacity with manual feeding, but studies on energy consumption and the forces developed in the system during the process are few or not at all. For baling a larger volume of material, it is necessary to repeat several times the compaction process with each time refilling the volume of the press chamber $[3 ; 5 ; 14]$.

The paper presents aspects and experimental results regarding the compaction of PET bottles of the same capacity, related to the variation of the compaction force with the displacement of the pressure plate, in several successive compressions, as well as the energy consumed in the compression process, for each compression-recompression, but also the total of this energy consumption.

\section{Materials and methods}

Vertical or horizontal flow presses with successive feeding and parallelepiped bales are used to compact the waste from plastic bottles. Experiments on the physical-mechanical characteristics of the compacted material and the forces resistant to compaction were performed on a vertical flow press type HSM-V 605 (GmbH, Germany) Fig.1, a. The determination of the data was done by mounting a data collection, recording and remote transmission equipment, indicated in Fig.1, b.

a)

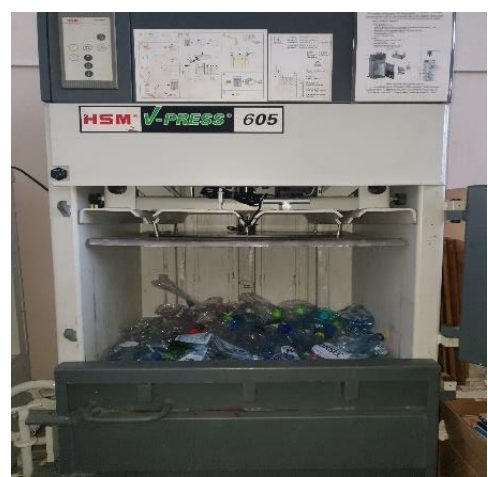

b)

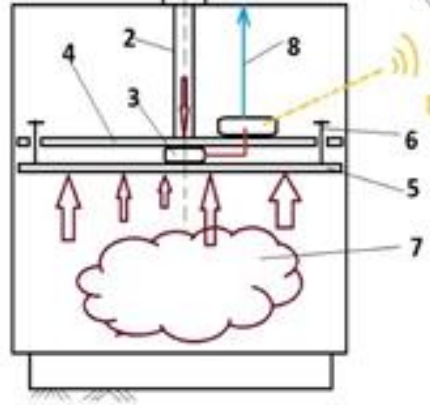

c)

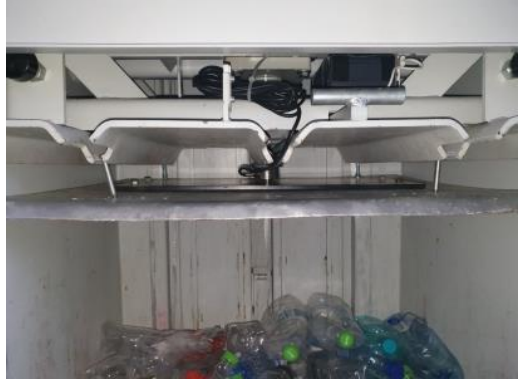

Fig. 1. HSM-V 605 vertical press for PET bales - overview (a), acquisition system (b), pressure plate (c): 1 - hydraulic cylinder; 2 - cylinder rod; 3 - button load cell; 4 - pressing plate; 5 - pressing support plate; 6 - guides for the support press plate; 7 - PET bottles;

8 - displacement sensor; 9 - laptop

a)

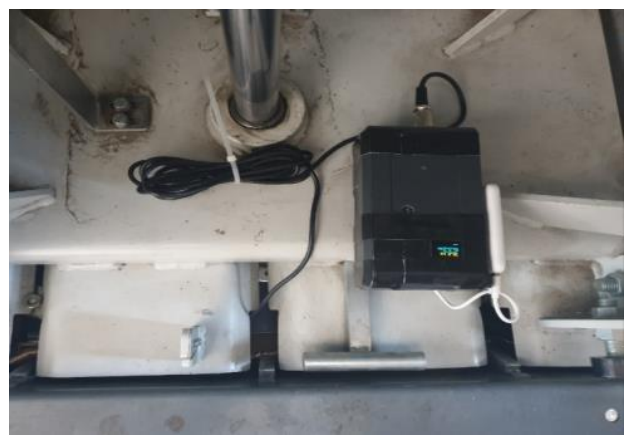

b)

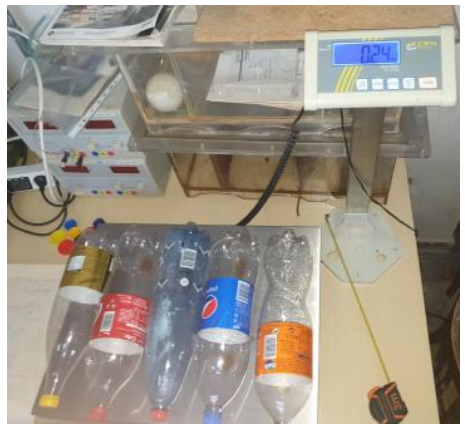

Fig. 2. HSM-V 605 vertical press equipped for experiments: a - distance sensor;

$\mathrm{b}-$ KERN balance weight $(60 \mathrm{~kg})$ for weighing material to be compacted

The press has a large press chamber (800x600x1045 mm), three-phase power supply (400 V), the maximum pressing force being $57 \mathrm{kN}$, with a pressing cycle time of about 21 seconds. The dimensions of the feeding window are 800x495 mm, and of the bale of 800x600x600 mm.

Equipment built and used in data collection and processing (Fig.1, b) consists of a development board ESP-WROOM-32 with processor ESP32-D0WDQ6 (Espressif Systems, China), mounted in a black box, with Wi-Fi and Bluetooth; a weight sensor reading module HX71 (button load cell) with 
operating voltage 2.7-5.5 V, $10 \mathrm{~mA}$. Load cell (position 3, Fig. 1, b), of $1000 \mathrm{~kg}$ (accuracy class C2), captures the pressing forces on the press plate in the vertical direction in order to determine their variation when compressing the material.

In addition to the two elements mentioned, to measure the distance travelled by the press plate a VL53L1X module (STMicroelectronics, Netherlands) was used, which uses a laser sensor for distances up to $4 \mathrm{~m}( \pm 5 \mathrm{~mm})$. The measurements can be read via the digital interface I2C. The board includes a linear regulator of $2.8 \mathrm{~V}$ and level switches that allow operation on a range of input voltages between 2.6-5.5 V. The system is powered by an external battery 2.7-3.6 V and operates at operating temperature between $-40{ }^{\circ} \mathrm{C}$ to $+85^{\circ} \mathrm{C}$. The acquisition system takes signals every second, both in terms of the movement of the pressure plate and in terms of the value of the recorded compression force.

The programming was done in $\mathrm{C}++$, on the embedded platform development framework in the VScode at the base of the kernel is the ESP-IDF toolchain integrated by the manufacturer, implemented based on free RTOS and high-level support for Arduino libraries, having at the same time access to the low level functions specific to the drivers in the ESP-IDF kernel.

The main components of the library software used are: a display control library that implements support for multiple display models - Adafruit HX711 amplifier control library; ToL VL53L1X sensor control library; standard communication libraries: wire and SPI; the standard library for the DNS server; standard library for asynchronous webserver; Arduino JSON format parser library.

Also, top-level std libraries were used for threading and timing, which have implemented in ESPIDF bindings for free RTOS, thus being able to be used without overhead.

There are thus 2 separate threads implemented on 2 tasks: a thread for the wifiManager responsible for the web interface and settings and a thread for measurement and display.

The experimental flow regarding the determination of the physical-mechanical characteristics and the behaviour of the waste of plastic bottles was made by:

- weighing and counting the bottles in the samples;

- introduction of material successively, sorted on the criterion of dimensional uniformity (2 litre bottles) in the pressing chamber;

- measuring deformation of the volume of waste plastic bottles;

- scaling the physical characteristics obtained (force, time, length of the pressing piston).

In the first stage, 2 litre PET bottles were used (with lid, but pricked with the tip of a knife in the middle area), unreformed, weighed both individually and in groups, which were compacted to the lowest limit reached by the press plate.

The pressing process proceeded as follows: enough bottles were loaded into the press chamber to cover the volume of the chamber ( 77 bottles, $3.850 \mathrm{~kg}$ - an average of 50 grams per bottle), followed by continuous pressing, until the lower limit detected by the system is reached and the pressure plate is raised automatically. After that a recompression was made and return of the pressure plate to the upper point, filling the remaining volume with other 53 bottles $(2.650 \mathrm{~kg})$ and a new compression to the limit detected by the system, then a recompression for better compaction. This was followed by another addition of the free volume of the press chamber (with 25 bottles $-1.250 \mathrm{~kg}$ ) and a three-stage compaction, for a compact placement of the bale for subsequent binding. The pressure plate had a free movement until it reached the top level of the bottles, after which its displacement followed a curvilinear variation, depending on the size of the compaction force at that time.

The experiment was repeated later, in approximately the same conditions, with the same types of bottles, the differences from the first being about $10.57 \%$, the paper presenting the average values of the two experiments, both in table form and in graphs form.Based on the graphs drawn in the MS Office Excel program, the areas under the force-displacement curve that represent the energy consumed at each stage of the compaction process were determined, and its values are presented at the bottom of the table.

\section{Results and discussion}

The experimental data obtained were stored in tabular form, these being generated continuously as long as the press was in operation (Table 1). The table shows the variations of the compaction force depending on the distance of movement of the compaction plate from a fixed upper point on the press cover and also the number of 2-litre PET bottles existing in the pressing chamber in each of the three- 
compaction stages, respectively their mass. Data processing can bring favourable results in order to model the process of pressing waste from plastic bottles.

From the analysis of data in Table 1 and also the graphs presented it is found that the pressure plate travels, at first, without load, a certain distance until it comes into contact with the material to be compacted. From now on, the values of the compressive forces are recorded, which increase relatively exponentially as the pressure plate descends and the maximum lower position of the piston is reached (respectively the maximum compaction force that the press presents). The lower the level of material inside the press, the later the recording of the compression force value will start.

Therefore, the variation of the compressive forces according to the displacement of the piston can be followed in Table 1, for all seven stages of compaction of 2-litre PET bottles. What is found, mainly, is that the force recording system starts to show values as soon as the press is loaded as close as possible to the top of the press chamber, as can be seen in Fig. 3 (right). Moreover, the higher the amount of material in the pressing chamber, the higher the pressing forces, both at the first compression and at the recompression.

Table 1

Variation of pressure forces with displacement of the compaction piston

\begin{tabular}{|c|c|c|c|c|c|c|c|c|c|c|c|c|c|}
\hline \multicolumn{14}{|c|}{ Successive compaction of 2.0 litre PET bottles } \\
\hline \multirow{2}{*}{\multicolumn{2}{|c|}{$\begin{array}{c}\text { P01.01 } \\
77 \text { bottles/ } \\
3.850 \mathrm{~kg}\end{array}$}} & \multirow{2}{*}{\multicolumn{2}{|c|}{$\begin{array}{c}\text { P01.02 } \\
77 \text { bottles/ } \\
3.850 \mathrm{~kg}\end{array}$}} & \multicolumn{2}{|c|}{ P02.01 } & \multicolumn{2}{|c|}{ P02.02 } & \multicolumn{2}{|c|}{ P03.01 } & \multicolumn{2}{|c|}{ P03.02 } & \multicolumn{2}{|c|}{ P03.03 } \\
\hline & & & & & $\begin{array}{r}130 \mathrm{~b} \\
6.50 \\
\end{array}$ & & \multicolumn{6}{|c|}{$\begin{array}{c}155 \text { bottles/ } \\
7.750 \mathrm{~kg}\end{array}$} \\
\hline$(1)^{*}$ & $(2)^{*}$ & $(1)$ & (2) & $(1)$ & (2) & $(1)$ & (2) & (1) & (2) & $(1)$ & (2) & $(1)$ & (2) \\
\hline 462 & 4.76 & 459 & 1.71 & 0 & 0.52 & 98 & 6.09 & 272 & 1.03 & 0 & 0.89 & 275 & 5.17 \\
\hline 493 & 17.44 & 488 & 13.53 & 0 & 0.65 & 120 & 21.00 & 291 & 2.24 & 4 & 0.94 & 294 & 14.71 \\
\hline 544 & 37.87 & 527 & 39.52 & 0 & 3.01 & 140 & 40.03 & 321 & 15.82 & 49 & 0.95 & 323 & 28.38 \\
\hline 581 & 73.95 & 561 & 75.87 & 17 & 8.64 & 180 & 59.26 & 347 & 39.85 & 80 & 1.02 & 351 & 45.59 \\
\hline 615 & 127.74 & 596 & 122.23 & 46 & 15.76 & 210 & 75.14 & 383 & 75.74 & 106 & 1.12 & 383 & \begin{tabular}{|l}
78.76 \\
\end{tabular} \\
\hline 651 & 139.14 & 638 & 179.21 & 79 & 26.26 & 243 & 89.32 & 415 & 125.68 & 130 & 1.13 & 419 & 119.11 \\
\hline- & - & - & - & 123 & 46.52 & 267 & 91.94 & 457 & 204.53 & 164 & 1.13 & 463 & 200.66 \\
\hline- & - & - & - & 163 & 70.54 & 295 & 136.73 & 512 & 287.70 & 205 & 1.16 & 502 & 288.45 \\
\hline- & - & - & - & 193 & 98.63 & 336 & 215.26 & 539 & 382.13 & 232 & 1.20 & 537 & 347.32 \\
\hline- & - & - & - & 227 & 120.62 & 381 & 257.95 & 582 & 504.94 & 260 & 1.43 & 575 & 425.8 \\
\hline- & - & - & - & 249 & 150.03 & 413 & 361.58 & 615 & 651.47 & 287 & 4.11 & 605 & 569.03 \\
\hline- & - & - & - & 280 & 192.17 & 511 & 600.85 & 659 & 567.11 & 315 & 9.96 & 646 & 715.62 \\
\hline- & - & - & - & 325 & 246.07 & 608 & 730.64 & - & - & 343 & 27.37 & 675 & 219.37 \\
\hline- & - & - & - & 367 & 277.63 & 657 & 518.07 & - & - & 375 & 46.65 & 595 & 29.10 \\
\hline- & - & - & - & 416 & 348.68 & - & - & - & - & 405 & 73.08 & - & - \\
\hline- & - & - & - & 470 & 380.30 & - & - & - & - & 436 & 108.35 & - & - \\
\hline- & - & - & - & 512 & 421.80 & - & - & - & - & 482 & 138.99 & - & - \\
\hline- & - & - & - & 553 & 500.86 & - & - & - & - & 524 & 205.23 & - & - \\
\hline- & - & - & - & 619 & 586.82 & - & - & - & - & 565 & 406.97 & - & - \\
\hline - & - & - & - & - & - & - & - & - & - & 602 & 521.61 & - & - \\
\hline- & - & - & - & - & - & - & - & - & - & 639 & 700.23 & - & - \\
\hline- & - & - & - & - & - & - & - & - & - & 670 & 170.92 & - & - \\
\hline \multicolumn{2}{|c|}{$131.553 \mathrm{~J}$} & \multicolumn{2}{|c|}{$134.065 \mathrm{~J}$} & \multicolumn{2}{|c|}{$1471.718 \mathrm{~J}$} & \multicolumn{2}{|c|}{$1729.953 \mathrm{~J}$} & \multicolumn{2}{|c|}{$1009.440 \mathrm{~J}$} & \multicolumn{2}{|c|}{$856.255 \mathrm{~J}$} & \multicolumn{2}{|c|}{$1053.150 \mathrm{~J}$} \\
\hline \multicolumn{4}{|c|}{$0.069 \mathrm{~kJ} \cdot \mathrm{kg}^{-1}$} & \multicolumn{4}{|c|}{$0.493 \mathrm{~kJ} \cdot \mathrm{kg}^{-1}$} & \multicolumn{6}{|c|}{$0.377 \mathrm{~kJ} \cdot \mathrm{kg}^{-1}$} \\
\hline
\end{tabular}

*(1) - Displacement, mm; (2) - Force, daN 

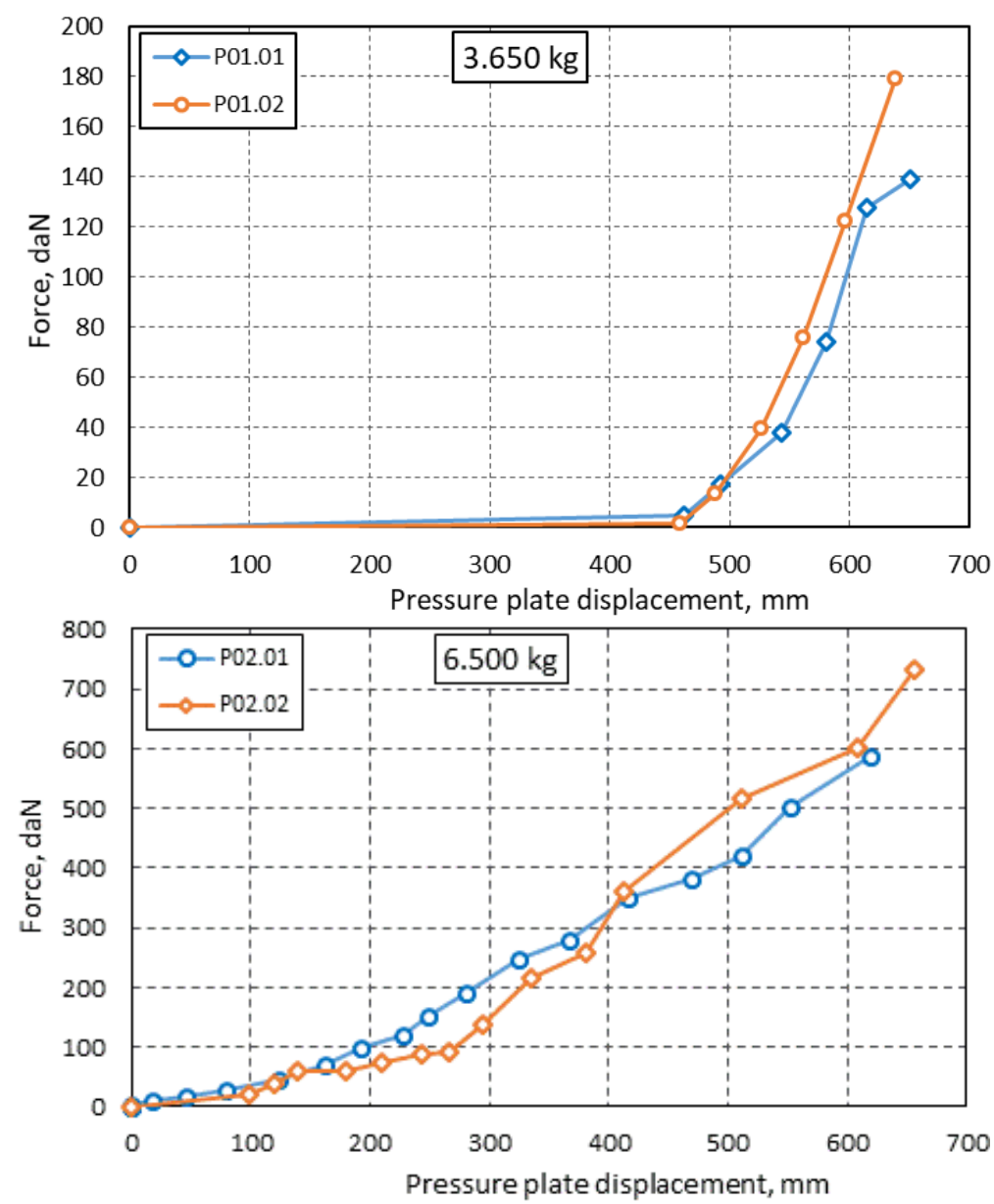

Fig. 3. Force - displacement variation recorded on the pressure plate: left - compressionrecompression 77 PET bottles (2 1); right - compression-recompression 130 PET bottles (2 1)

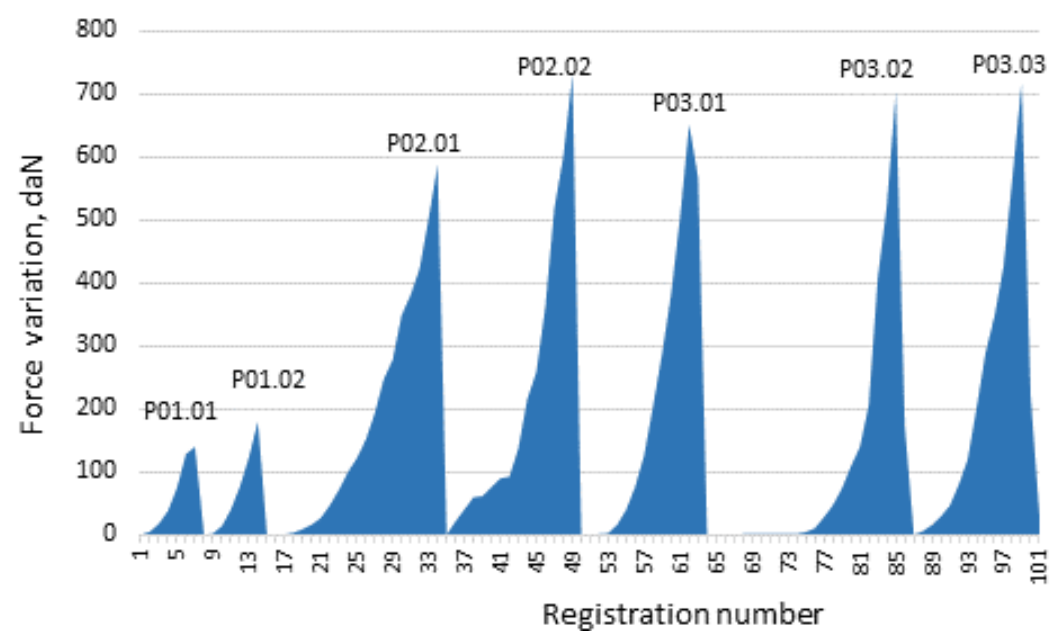

Fig. 4. Variation of the pressing force in the seven phases of the PET bottle compaction process: P01 - 77 bottles, $\mathrm{P} 02-77+53$ bottles; $\mathrm{P} 03-130+25$ bottles

In addition to the data that can be observed directly from the data table or from the graphs presented it was found that the speed of the press plate during the compression of the bottles differs from one pressing to another. Compression of the bottles is as long as the plate is in direct contact with the material to be compacted and the force increases continuously. Thus, it showed the values from $53.0 \mathrm{~mm} \cdot \mathrm{s}^{-1}$ at the first pressing to about $47.3 \mathrm{~mm} \cdot \mathrm{s}^{-1}$ at the last pressing, with variations between these values at the other stages of pressing. However, the value of the speed of the press plate depends on the compressive strength of the material, at least for the press we used. 
In Fig. 5 it is observed that only the steeper portion of the seven curves, representing the seven stages of compaction, represents the contact of the press plate with the material to be compacted. On the anterior areas, the pressure plate has either not yet touched the material, or the compaction force is very small (practically imperceptible).

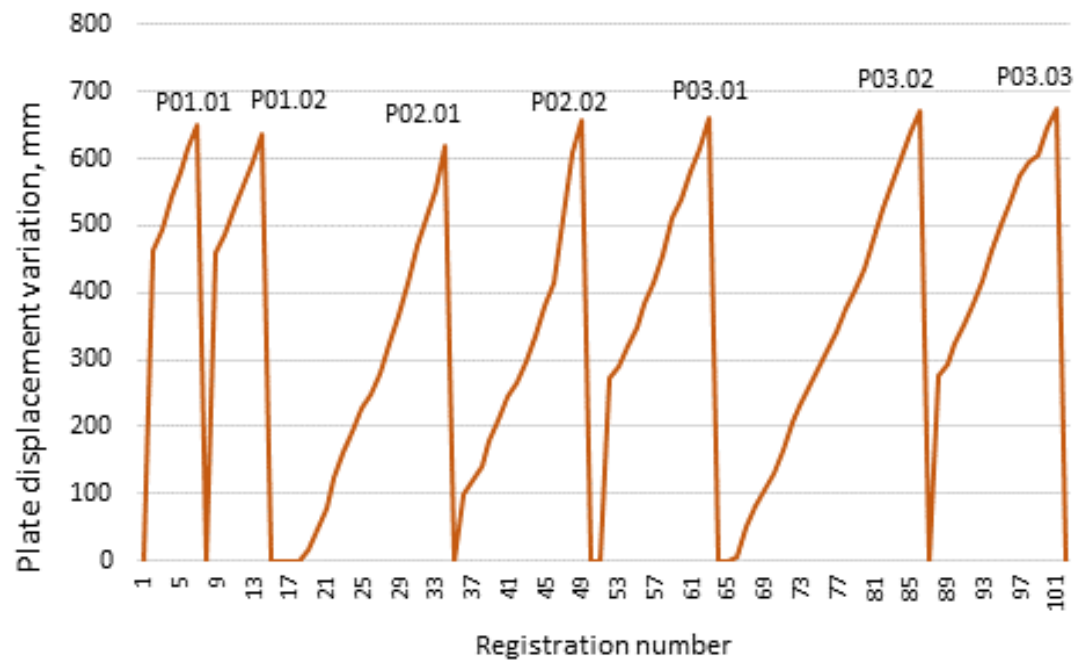

Fig. 5. Variation of pressure plate displacement in the compaction process of PET bottles: $\mathrm{P} 01-77$ bottles, $\mathrm{P} 02-77+53$ bottles; $\mathrm{P} 03-77+53+25$ bottles

Generally, the initial position of the PET bottles in the compaction process was horizontal and just sometimes could reach an inclined one.

Analysing the values of energy consumption in the three stages of compression, it can also be seen that the highest values are presented by the second stage (pressing P02.01 and P02.02), when the number of compaction bottles has increased a lot compared to the first stage (P01). If in the first stage the energy consumption is low $(131.5 \mathrm{~J}$, respective $134.1 \mathrm{~J})$, in the second stage the energy consumed in compression reached $1471.7 \mathrm{~J}$, respective $1729.9 \mathrm{~J}$. In the third stage of compaction the energy consumed decreases, although other 25 bottles were added to the pressing chamber. What seems logical, however, are the decreasing energy values at the next two recompressions (decreasing from about 1009.4 $\mathrm{J}$ at $\mathrm{P} 03.01$ to about 856-857 $\mathrm{J}$ at compressions P03.02 and P03.03). The specific compression energy of the 2-litre bottle group differs from the degree of supply of the press. For the three feeding phases the specific energy changes from about $0.070 \mathrm{~kJ} \cdot \mathrm{kg}^{-1}$ at the first feeding, to about $0.400 \mathrm{~kJ} \cdot \mathrm{kg}^{-1}$ at the last supply with bottles. Overall, the total compression energy (consumption amount from the seven compression) reaches approx. $6386 \mathrm{~J}$, which relative to the mass of the bottles in the pressing chamber $(7.750 \mathrm{~kg}$ ) determines the specific pressing energy, that is, $824.01 \mathrm{~J}$ per $1 \mathrm{~kg}$ of compacted bottles.

As it can be seen in Fig.2, the allure of the force-displacement curves is similar, possibly having several different slope areas. From the regression analysis of the experimental data it was observed that in six of the seven stages of compaction the force-displacement correlation has a linear variation, with the $\mathrm{R}^{2}$ coefficient of over 0.930 , on the area on which the load acts, in accordance with other scientific papers $[6 ; 7 ; 9 ; 15]$.

\section{Conclusions}

Our research continues with the compaction of PET bottles of $1.51,11$, respectively 0.51 , in a random location in order to identify the contribution of each type to the mixed compaction of used bottles.

When pressing 2-litre PET bottles, with the vertical press of $57 \mathrm{kN}$ the compression forces showed variations, generally increasing, when recompressing or adding new material. For maximum press loading (according to the experiments with $7.750 \mathrm{~kg}$ PET bottles) the compressive force exceeded the value of $715 \mathrm{daN}$ at the third compression, i.e., a pressure of about $15000 \mathrm{~Pa}$.

In terms of compression energy, it recorded the highest values when the press was suddenly reloaded with a larger amount of material, after the initially loaded material had been compressed in two 
stages. Thus, the energy consumed increased more than ten times when the amount of material in the press almost doubled (from $3.850 \mathrm{~kg}$ to $6.500 \mathrm{~kg}$ ), and the pressure plate moved under loads over a longer distance, noticed earlier by the registration system. However, the average value of the specific compression energy for the whole process was around $0.824 \mathrm{~kJ} \cdot \mathrm{kg}^{-1}$ of the compressed material.

\section{References}

[1] Singh N., Hui D., Singh R., Ahuja I.P.S., Feo L., Fraternali F., Recycling of plastic solid waste: A state of art review and future applications, Com.posites Part B, 2017, 115, pp. 409-422. DOI: 10.1016/j.compositesb.2016.09.013

[2] Foolmaun R.K., Ramjeawon T., Disposal of post-consumer polyethylene terephthalate (PET) bottles: Comparison of five disposal alternatives in the small island state of Mauritius using a life cycle assessment tool, Environmental Technology, 2012, 33(4-6), pp. 563-572, DOI: $10.1080 / 09593330.2011 .586055$

[3] Inao C.S., Corey A.H.V., Mekonnen A., Design and development of waste compactor for plastic bottles, metal cans, and papers, Mechanical Engineering, 6 p. [online][21.03.2021] Available at: https://www.academia.edu/37291860.

[4] Akinola A., Adeyemi I., Adeyinka F., A Proposal for the management of plastic packaging waste, IOSR-JESTFT, 8(1), 2014, pp.71-78, DOI: 10.9790/2402-08117178.

[5] Jankauskaite V., Lygaitis G., Lygaitis R., Polyethylene terephthalate waste recycling and application possibilities: a Review, Materials Science, 14(2), 2008, pp.119-127.

[6] Ivanova T., Muntean A., Havrland B., Pobedinsky V. Theoretical modelling of the briquetting process with different pressing equipment, Agronomy Research, 2013, 11(1), pp. 47-52.

[7] Pavlovic A., Fragassa C. , Vegliò L., Vannucchi de Camargo F., Minak G. Modeling palletized products: the case of semi-filled bottles under top-load conditions, Appl. Sci., 2020, 10, 332 p. DOI: 10.3390/app10010332

[8] Gageanu I., Cardei P., Matache M., Voicu Gh. Researches on the statistical modelling of the processes of pelleting biomass, testing classic powder compaction models, INMATEH Agricultural Engineering, Vol. 59, No. 3, 2019, pp.119-124, DOI: 10.35633/INMATEH-59-13

[9] Herak D., Sleger V., Mizera C., Sedlacek A. Mechanical behaviour of bulk rapeseeds under quasi dynamic compression loading, Engineering for rural development, 2015, Jelgava, pp. 28-32.

[10] Welle F. Twenty years of PET bottle to bottle recycling - An overview, Resources, Conservation and Recycling, 55(11), 2011, pp. 865-875. DOI: 10.1016/j.resconrec.2011.04.009.

[11] Archna A., Moses V., Sagar S., Shivraj V., Chetan S. A Review on Processing of Waste PET (Polyethylene Terephthalate) Plastics, International Journal of Polymer Science Engineering, vol. 1, iss. 2, 2015, pp.1-13. DOI: 10.37628/ijpse.v1i1-2.120.

[12] Gulseven O., Ashkanani S., Abdullah S., Ismaeil H., Alkandari H., Baroun M. A sustainable model for enhancing road quality with recycled plastic bags, Kuwait Journal of Science. 46(4), 2019, pp.112-119.

[13] Akcaozoglu S., Atis C.D., Akcaozoglu K. An investigation on the use of shredded waste PET bottles as aggregate in lightweight concrete, Waste Management, 30(2), 2009, pp. 285-290. DOI: 10.1016/j.wasman.2009.09.033.

[14] Afzalinia S., Roberge M., Modeling of the pressure-density relationship in a large cubic baler, Journal of Agricultural Science and Technology, 2012, 15(1), pp. 35-44.

[15] Dosta M., Costa C., Al-Qureshi H.A. Numerical investigation of compaction of deformable particles with bonded-particle model, The European Physical Journal Conferences, 2017, 140:15021, DOI: 10.1051/epjconf/201714015021 